\title{
ALTERIDAD E IDENTIDAD EN LA NOVELA LOS TOPOS DE FÉLIX BRUZZONE. LA TEMPORALIDAD INSCRIPTA EN LA HISTORIA LITERARIA ARGENTINA
}

Ana María Hernando ${ }^{17}$

RESUMEN: Este trabajo intenta "leer" en el sentido derrideano, la novela de Félix Bruzzone, Los Topos, publicada en el año 2008, texto que plantea una nueva alternativa de escribir literatura y nos enfrenta con una diferente "realidad" escritural. Estamos escuchando y sintiendo la voz de un hijo de desaparecidos, como consecuencia de la Dictadura Militar (1976-1983), una voz narradora sin nombre, como sin nombre fueron muchos de los hijos dispersados en el territorio argentino. Es posible afirmar que la narrativa escrita en Argentina en las últimas décadas del siglo XX -más precisamente después de la Dictadura Militar-, y en lo que va del XXI, puede estar inscripta en el marco de una crisis de la representación realista, en el ámbito de la manifestación de un conjunto de tendencias estéticas que trabaja sobre problemas constructivos de identidad y de alteridad, de emergencia de discursos y de relación entre identidad y literatura, entre otros problemas de género. Narrativa muy diversa que muestra la pluralidad genérica y un abanico de estilos escriturales -el policial, el ensayo, la novela testimonial y la literatura de "versiones", entre otros hechos de lenguaje-, a los que se suma la tendencia a la crítica al presente, a la complejidad de lo contado y a la necesidad de subvertir el discurso único y hegemónico del autoritarismo. Así es posible detectar la aparición de un "nuevo realismo" ficcional acorde con la historia vivida y padecida en la Argentina, en los tiempos aciagos de la Dictadura Militar. Los Topos es una vuelta de tuerca de la historia que quiere escribirse para permanecer como alegoría estética y como testimonio de las consecuencias de políticas equivocadas. Novela

\footnotetext{
${ }^{17}$ Doctora en Ciencias Humanas en el Campo de los Estudios Literarios. Profesora en la Universidad Nacional de Córdoba UNC. SECyT, Secretaria de Ciencia y Tecnologia. Facultad de Lenguas. Universidad Nacional de Córdoba.
} 
que marca el quiebre y la aparición de una nueva generación literaria transgresora, que quiere contar la historia nacional reciente.

Palabras Clave: búsqueda- desaparecidos- topos- realismo epocaldictadura militar.

RESUMO: Este trabalho tenta "ler" no sentido derrideano, o romance de Félix Bruzzone, Los Topos, publicado em 2008, texto que estabelece uma nova alternativa de escrever literatura e nos depara com uma nova "realidade" escritural. Ouvimos e sentimos a voz de um filho de desaparecidos, vítima da Ditadura Militar (1976-1983), uma voz narradora sem nome, como também foram sem nome muitos dos filhos espalhados pelo território argentino. É possivel afirmar que a narrativa escrita na Argentina das últimas décadas do século XX -precisamente depois da Ditadura Militar-, e nesses primeiros quinze anos do XXI, pode estar inscrita no marco de uma crise da representação realista, no âmbito de manifestação de um conjunto de tendências estéticas que trabalha sobre problemas de construção de identidade e alteridade, de emergência de discursos e de relação entre identidade e literatura, dentre outros problemas de gênero. Narrativa muito diversa que mostra a pluralidade genérica e um leque de estilos escriturais -o policial, o ensaio, o romance testimonial e a literatura de "versões", dentre outros fatos de linguagem-, aos quais acrescenta-se a tendência à crítica ao presente, à complexidade do narrado e à necessidade de subverter o discurso único e hegemônico do autoritarismo. Assim é possivel detectar o surgimento de um "novo realismo" ficcional de acordo com a história vivida e sofrida na Argentina, nos tempos aziagos da Ditadura Militar. Los Topos é uma guinada na história que quer se escrever para permanecer como alegoria estética e como testemunha das consequências de políticas erradas. Romance que marca a quebra e a aparição de uma nova geração literária transgressora, que quer contar a história nacional recente.

Palavras-chave: busca- desaparecidos- topos- realismo epocal- ditadura militar 
Esta Ponencia intenta "leer" en el sentido derrideano ${ }^{18}$, la novela de Féliz Bruzzone, Los Topos, publicada en el 2008, texto que plantea una nueva alternativa de escribir literatura y nos enfrenta con una diferente "realidad" escritural. Un modo de apropiación a una variedad de discursos heredados sobre la historia nacional argentina. Estamos escuchando y sintiendo la voz de un hijo de desaparecidos, como consecuencia de la Dictadura Militar (1976-1983), una voz narradora sin nombre, como sin nombre fueron muchos de los hijos dispersados en el país argentino.

Las grandes corrientes estéticas llevan en su interior sus alternativas, sus matices y sus variadas expresiones. Así, el Realismo, el Romanticismo y también las Vanguardias, se manifestaron en distintos momentos recogiendo en el lenguaje, en las estructuras y en las formas discursivas, la temporalidad epocal y la espacialidad territorial. Esta novela, según decíamos, muestra una "nueva realidad": la de un autor que es hijo de desaparecidos. Texto que reconstruye un período histórico, político, social y cultural de la Argentina; texto que plasma, desde la mirada del narrador, a veces inquisidora, otras evasiva, como también "realista" y por momentos fantasiosa y hasta cómica, los años aciagos de la Dictadura Militar.

La literatura es una estética que tiene la condición y el derecho de hablar de temas de la "realidad". Los Topos, que como dice Beatriz Sarlo (Buenos Aires, Argentina, 1942) se afirma en el derecho de hablar sobre los desaparecidos, habla de una "realidad" presente en la República Argentina -la de la década de los 70-, y de la ausencia de padres desaparecidos, haciendo de este modo realismo autobiográfico, pero también es posible hablar de realismo político, evocación, parodia, grotesco y hasta novela detectivesca o policial, entre otros elementos y matices que circulan en la misma novela. Surge así lo que se podría llamar una nueva línea de escritura, la de la "reivindicación realista" expresada desde la ficción de una novela, pero que da cuenta de fragmentos "reales" de la vida de hijos de desaparecidos, como del enjuiciamiento, desde la sociedad, a los responsables del exterminio.

\footnotetext{
${ }^{18}$ Para Derrida la deconstrucción sería una forma de lectura sin limites, porque la lectura es infinita; un trabajo, una tarea, un hacer, una escritura, un hacer temblar o vacilar el edificio desde dentro. No hay un sentido en el texto a develar, sino un jugar entre el adentro y el afuera, un habitar.
} 
Es el propósito de esta Ponencia elucidar el quiebre y la aparición de una nueva generación literaria transgresora, que se apropia de una variedad de discursos heredados, pero también vivenciados, acerca de la "realidad" nacional experimentada hace unas décadas. Hay una vuelta de tuerca de la historia del relato del realismo epocal de fines del siglo XIX, de aquel realismo concebido como una corriente estética que luego atravesará el siglo sin perder frescura, y que poseen muchos pueblos del universo. La definición de este realismo ya se encuentra en la Poética de Aristóteles, en el principio de la mímesis -que señala tres maneras de imitar la realidad: como es, mejor de lo que es y peor de lo que es-, realismo que avanza en una transformación hacia otro tipo de realismo, que quiere escribirse para permanecer como alegoría estética y como un testimonio de las consecuencias de políticas equivocadas.

Es posible hacer un reconocimiento en el texto a analizar, de las "huellas de una dictadura" y señalar distintas expresiones de la época, como diversos momentos de sus manifestaciones, y también el contexto histórico-político y social. De este modo, también se puede afirmar que la narrativa escrita en Argentina en las últimas décadas del siglo XX -más precisamente, después de la Dictadura Militar-, y en lo que va del XXI, puede estar inscripta en el marco de una crisis de representación realista, en el ámbito de manifestación de un conjunto de tendencias estéticas que trabajan sobre problemas constructivos de identidad y de alteridad, de emergencia de discursos y de relación entre "realidad" y literatura, entre otros problema de lo literario. Este corpus se expresa a través de una pluralidad genérica, un abanico de estilos escriturales -el policial, el ensayo, la novela testimonial y la literatura de "versiones", entre otros hechos literarios-, a los que se suma la tendencia a la crítica al presente, a la complejidad de lo contado y a la necesidad de subvertir el discurso único y hegemónico del autoritarismo. Escritura donde es posible observar la desaparición de las utopías realistas clásicas en pro de privilegiar ciertos usos del lenguaje. En síntesis, podemos detectar la aparición de un "nuevo realismo" ficcional acorde con la historia vivida y padecida en la Argentina en un tiempo ya histórico.

\section{HUELLAS DE UNA DICTADURA MILITAR}

Este trabajo también se propone señalar un seguimiento de las huellas de la última Dictadura Militar en Argentina en diversos textos fílmicos y literarios que muestran distintos momentos. En primer lugar, a 
Alteridad e identidad en la novela Los Topos de Félix Bruzzone. La temporalidad inscripta en la historia literaria argentina | 77

partir de la precisa contextualización del momento histórico, se especifican las transformaciones producidas, con especial atención a la represión en el ámbito de la cultura. Se visualizan las expresiones escapistas - el film La Mary (1974)- y aquellas otras que, a través de la elipsis como recurso, metaforizan dicha situación -el film Últimos días de la víctima (1982) y la novela Respiración artificial (1988) de Ricardo Piglia-, film y novela que atestiguan lo expresado.

Nos proponemos ahora, brevemente, delinear el "marco históricopolítico-cultural y social” que constituye puntos de inflexión en la vida argentina de las últimas décadas del siglo XX y, como consecuencia, la violencia político-social que signa el corpus literario y fílmico de esos años. En un contexto social y político determinado y en un espacio geográfico dado -Argentina-, se muestran los desaparecidos, los secuestros, el gobierno de facto, las fuerzas parapoliciales y paramilitares, y las persecuciones, entre otros.

Al mismo tiempo, queremos reflexionar y explicitar sobre un corpus específico -de extensión sincrónica y diacrónica-, de un segmento de la novelística y del cine argentino producidas entre 1975 y la actualidad. Es posible también documentar los conocimientos citados, integrados en una tradición de autoritarismo, tanto del maniqueísmo militar como de las políticas de Estado, lo que nos permite problematizar las distintas visiones y teorias explicativas que buscan referenciar y construir la memoria sobre la última Dictadura Militar en la Argentina.

De este modo, se puede elaborar un recorrido por las huellas "culturales, sociales y políticas" de la última Dictadura Militar. Estas huellas muestran las distintas miradas que desde la historia, el cine y la literatura se han realizado, en un intento por representar -tanto en la metaforización como en la referenciación- dicho momento histórico. De tal manera se problematizan las visiones de un pasado aún no resuelto en la sociedad argentina. En términos de Jacques Derrida (El Biar, Argelia francesa 1930 - París, 2004), ¿es posible perdonar?, ¿en qué condiciones?, ¿se puede perdonar cuando las heridas permanecen abiertas?.

\section{CONTEXTUALIZANDO LO POLÍTICO-SOCIAL}

El feroz enfrentamiento entre la derecha y la izquierda peronista estalló en junio de 1973, en el momento de la llegada de Perón al aeropuerto de Ezeiza. El episodio dejó a la vista una lucha que hasta 
entonces había estado oculta. Marcó también el avance de las organizaciones armadas de la derecha, La Alianza Anticomunista Argentina (AAA), conocida como Triple A, que iniciaron una cadena de atentados y asesinatos que tuvieron como blanco ya no sólo a la izquierda peronista o a los grupos armados marxistas, sino a la izquierda en general. Fueron asesinados intelectuales, estudiantes, dirigentes sindicalistas combativos y se amenazó de muerte a artistas, escritores, periodistas, ideólogos y militares de izquierda, que en muchos casos marcharon al exilio. Se practicaba el terrorismo de estado en un marco constitucional.

La lucha se hizo cada vez más sangrienta, porque los Montoneros y el ERP, Ejército Revolucionario del Pueblo, por su parte, continuaron atacando a militares, empresarios y sindicalistas de la derecha, -actitud anticonstitucional y antidemocrática-, durante la vigencia del gobierno constitucional. Hubo asaltos a cuarteles militares y policiales, como así también atentados con bombas y asesinatos a sectores y funcionarios del gobierno. Hacia fines del período constitucional de María Isabel Martínez de Perón, un decreto del Poder Ejecutivo ordenó a las Fuerzas Armadas combatir a las organizaciones armadas de izquierda que operaban en la selva de Tucumán, demostrando que el gobierno era incapaz de garantizar la seguridad individual y social.

En este contexto se rompe el orden constitucional con un golpe ilegal, llamado Proceso de Reorganización Nacional, que es el nombre con el que se autodenominó la Dictadura Militar que tomó el Estado Argentino entre 1976 y 1983, como consecuencia del Golpe de Estado ejecutado el 24 de marzo de 1976. Golpe que depuso al gobierno constitucional de Isabel Martínez de Perón e instaló en su lugar a una Junta Militar encabezada por los Comandantes de las tres Fuerzas Armadas: Jorge Videla (Ejecutivo), Emilio Massera (Armada) y Orlando Agosti (Fuerza Aérea).

En esta época se advierte también, el control y la persecución de la izquierda argentina, y la militarización de la sociedad con la declaración y ejecución de la Guerra por Malvinas

\section{LA TEMPORALIDAD INSCRIPTA EN LA HISTORIA LITERARIA ARGENTINA}

En la Argentina, a partir de los años 70, y motivados por los acontecimientos que vivió nuestra sociedad como consecuencia de la Dictadura Militar, los narradores utilizan los géneros intimos, ya sean 
Alteridad e identidad en la novela Los Topos de Félix Bruzzone. La temporalidad inscripta en la historia literaria argentina | 79

autobiografías, memorias, diarios, cartas o autoficciones, entre otros, es decir, aquello que recientemente se ha englobado en el "testimonio" como género literario, para contar sus historias de vida, en este caso, los horrores vividos y padecidos como consecuencia de la llamada "guerra sucia”.

Existe el vínculo entre testimonio e interpretación. El testimonio asume la forma literaria del relato y se considera una práctica de escritura que intenta expresar una temporalidad originaria, que se recupera para ser contada en el presente. Un testimonio que requiere de una interpretación que se concreta en el marco de la historicidad y que está inscripto en una tradición cultural expresada en un texto. De esta manera, testimonio e interpretación funden sus horizontes en el sentido "gadameriano" 19 del término. Significa, fundamentalmente, un acto de higiene vital y mental y se convierte, además, en un remedio contra el olvido.

Es frecuente observar la estrecha correlación que existe entre la periodización de los fenómenos literarios y la periodización de la historia política. Los acontecimientos vividos por la sociedad argentina con el advenimiento de la Dictadura Militar a partir de la década del 70, a través de diversos tipos de mediación socio-discursiva, se expresaron como categorías estético-políticas en el discurso literario. Son hechos que se formalizan en contenidos que reflejan situaciones de vida, por un lado, y procesos mentales, por el otro, vinculados, ambos, con determinados momentos históricos. De esta manera, existen múltiples lazos entre los acontecimientos políticos de una época y de una sociedad dada, y la producción literaria de ésta.

La noción de Literatura, como también la de Historia, está relacionada con la episteme de una sociedad y de una cultura. Así, el "discurso" político y el accionar militar en la época de la Dictadura Militar, tuvieron un peso muy fuerte en un sector de la dirigencia política, cultural, intelectual e ideológica de los argentinos que se reflejó en el discurso literario y fílmico, imprimiéndole tendencias escriturales marcadas por las situaciones vividas y padecidas, como lo fueron el exilio

\footnotetext{
${ }^{19}$ Fusión de horizontes es lo que propone Gadamer en Verdad y Método, que sería el lugar de encuentro entre un acontecimiento histórico y un acontecimiento de la palabra, que se expresa en el texto literario.
} 
-en todas sus versiones-, el desarraigo, los secuestros y el exterminio, entre otros.

\section{ETAPAS EN LA ESCRITURA ARGENTINA}

Es posible distinguir un diferente tiempo de escritura en la literatura argentina durante el período que se corresponde con la Dictadura Militar o que hace referencia a ella. Etapa con distintas manifestaciones literarias y artísticas, en especial las vinculadas con la represión y opresión en el ámbito de la cultura. Son nuevas formas narrativas que caracterizan la producción literaria de mediados de la década del setenta y principios de los ochenta que se inscriben en el marco de la crisis de la representación. La organización autoritaria de la cultura llevada a cabo por la opresiva Dictadura Militar en la Argentina, pone en suspenso las antiguas creencias y deja afuera los habituales sistemas de interpretación. Las anteriores formas de aprehender la "realidad" resultan no suficientes frente a un conjunto de experiencias sociales fragmentadas y contradictorias sufridas por sujetos divididos. Ante esta nueva y "ominosa" realidad se torna necesaria la idea de encontrar un significado y un sentido a esta experiencia. En consecuencia, muchas de las narraciones de esos años renuncian al proyecto de reproducir lo "real", jugándose en la producción de sentidos incompletos y fragmentados. En síntesis, en la producción de sentidos "otros". Esta refutación de la mímesis tiene en su base el reconocimiento de que la historia ha estallado y que, en consecuencia, no puede recomponerse narrativamente desde un solo punto de vista o un solo discurso. El discurso de ficción se coloca opuesto al discurso autoritario, y se cuestiona sobre la historia que narra y sobre las modalidades con las cuales se narra. Así surge un corpus importante de textos producidos en estos años aciagos de la Dictadura Militar, corpus que busca la clave del presente en el pasado político, social y cultural.

En primer lugar, es importante destacar -como ya lo advertimos-, que la crítica especializada suele especificar las transformaciones producidas en este tiempo con ciertas expresiones escapistas, y aquellas otras que, a través de la elipsis como recurso, metaforizan dicha situación. La novela Respiración Artificial (1980) de Ricardo Piglia ${ }^{20}$ y el film Últimos

${ }^{20}$ La obra, elogiada por la critica, tiene un significativo epigrafe de T.S. Eliot: "We had the experience but missed the meaning, an approach to the meaning restores the experience" 
Alteridad e identidad en la novela Los Topos de Félix Bruzzone. La temporalidad inscripta en la historia literaria argentina $\mid 81$

días de la víctima (1982), -basado en la novela homónima de José Pablo Feinmann (1979)-, son dos manifestaciones de lo expresado.

Novelas como Cuerpo a cuerpo (1979) de David Viñas, En esta tierra dulce (1984), de Andrés Rivera; y otros textos de Ricardo Piglia como La Invasión (1967), Nombre falso (1975), Prisión perpetua (1989), La ciudad ausente (1992), dan referencia de la situación argentina.

Es posible reconocer otro momento, el conocido o llamado "del testimonio" o el de "la referencia del hecho" contado desde la visión de "los dos demonios", es decir, de una sociedad víctima de la dictadura, por un lado, y del accionar guerrillero, por otro, como lo manifiesta Abel Pose (Córdoba, Argentina, 1934) que adhiere a la teoría de los dos demonios. El testimonio en la película La noche de los lápices (1968) y en La historia oficial (1985) son contundentes. En Plata dulce (1982) se hace referencia a la crisis moral de la sociedad argentina; la novela Recuerdos de la muerte, de Bonasso Miguel (1984) y los testimonios que aparecen en Nunca Más (1984), entre otros, son ejemplificativos.

En los 90 asistimos a un cambio de actitud como consecuencia de las "leyes de obediencia debida" y "del perdón", medidas asumidas desde el gobierno, pero desde la literatura se sigue insistiendo en señalar lo pasado a partir del análisis de las causas y de las consecuencias. En las novelas No habrá más penas ni olvido (1980) de Osvaldo Soriano ${ }^{21}$, La vida entera (1981) de Juan Martini y El vuelo del tigre (1984) de Daniel Moyano, se reflexiona sobre cómo ordenar las experiencias dentro de la historia, desde dónde se controlan los lugares de poder y de qué manera se puede organizar una historia que se oponga al discurso oficial.

Así, es posible advertir que se empieza a transformar el sentido de "víctima" por el sentido de "héroe". Ya más adelante, las novelas La mujer

(Teníamos la experiencia pero perdimos su sentido, acercarse al sentido restaura la experiencia)- es la clave para entender la novela.

${ }^{21}$ La novela relata la lucha interna en la localidad de Colonia Vela entre peronistas de izquierda y peronistas de derecha. A grandes trazos, es una reflexión sobre éste movimiento politico durante aquellos turbulentos años. A pesar de su demorada fecha de publicación, esta novela no fue escrita -como se afirma- en Bélgica, donde Soriano se exilió en 1976 al comenzar la última dictadura cívico-militar, sino que fue escrita en el año 1974 mientras estaba aún en el pais, concretamente en la ciudad de Capitán Sarmiento, y ya se vislumbraba un futuro desolador, cruel y dictatorial. 
en cuestión (2003) de María Teresa Andruetto y Paisaje antes de la gran tormenta (2005) de Daniel Geisser, entre otras, dan cuenta de ello.

Finalmente, ya iniciado el siglo XXI, por un lado, aparece la "posmemoria", que es la búsqueda de los hijos de los desaparecidos sobre el vacío que dejó la ausencia de sus padres -film Los Rubios (2003) de Albertina Carri-, y a su vez, el relato de lo cotidiano que desmitifica el heroísmo de aquellas épocas para centrarse en el carácter común de los protagonistas y en la permanencia de aquellas problemáticas en los habitantes de este país. Aquí se puede señalar El mejor enemigo (1984) de Fernando López y los últimos cuentos de Andrés Rivera. En una línea de sintesis entre estas dos últimas manifestaciones, podemos ubicar a Los Topos (2008) de Félix Bruzzone. Es decir, se produce la "revisión crítica a través de la memoria”, representada por el accionar de ciertos jóvenes y de las "Madres de Plaza de Mayo", esas "mujeres de pañuelos blancos". Y, así, los hijos de los desaparecidos durante la Dictadura Militar irrumpen en la esfera nacional reclamando justicia social.

La aparición de los "hijos" con sus justos reclamos, se suma, de este modo, a las demandas de justicia que venían haciendo diferentes organizaciones gubernamentales y no gubernamentales, pidiendo estos jóvenes algún dato que les permita reconstruir la suerte seguida por sus padres, como también intentando la búsqueda de sus identidades en esa construcción de la memoria individual y colectiva. Los Topos pertenece a esta etapa. En suma, a partir de la recepción de los distintos textos y films, se recuperan las huellas de la Dictadura y su transformación, en cada nueva mirada.

Los polos de la ficción-realidad, de lo verosímil-inverosímil, de la realidad-irrealidad, como también los ejes relativos a los relatos tenebrosos, las voces reprimidas, las descripciones del terror y del horror, expresadas en la violación de los derechos humanos, y la ruptura de un silencio prolongado, son algunas de las notas caracterizadoras que se amalgaman y se entremezclan con la llegada del fin de la Dictadura Militar y el inicio de la Democracia en la Argentina.

\section{LA BÚSQUEDA}

Con un epígrafe de Federico Moura que dice textualmente, encontrarte en algún lugar/aunque estemos distantes/tantos odios para curar/ 
Alteridad e identidad en la novela Los Topos de Félix Bruzzone. La temporalidad inscripta en la historia literaria argentina | 83

tanto amor descartable ${ }^{22}$, y que traduce lo vivido y lo sufrido por hombres y mujeres, hijas e hijos de desaparecidos como consecuencia de la Dictadura Militar, se inicia la novela de Félix Bruzzone.

Los Topos es un texto con contenido dramático por la temática que aborda y la personalidad de sus protagonistas, pero también con bordes y sesgos cómicos, fantasiosos y oníricos. Tiene como referencia lo acontecido durante la Dictadura Militar, donde un hijo de desaparecidos, víctima de ese momento socio-político cultural que vivió y padeció la Argentina, cuenta su historia.

Se producen acontecimientos de la vida "real" que, si bien se pueden considerar exteriores a la literatura y ubicarlos como vinculados con los "derechos humanos", es un acontecimiento que incide en la cotidianeidad de la vida, que luego se ficcionaliza. Acontecimiento fundamental, como es la recuperación por parte de las ABUELAS DE PLAZA DE MAYO, de la identidad nacional de 117 nietos-hijos de desaparecidos a la fecha, en el año 2015. Otro acontecimiento fue la puesta en marcha de HIJOS, asociación que plantea tácticas y estrategias con las cuales se puede estar o no de acuerdo; y la restitución del edificio de la ESMA, hecho que se desplaza hacia un terreno ideológico y politico. Tres situaciones presentes en el texto de Bruzzone que, si bien se erigen en hechos de política de Estado, crean situaciones de escritura y entran en el canon de la literatura.

El primer espacio que se ubica en la narración es Buenos Aires, que se corresponde con la primera parte de la novela, en la que la búsqueda de la identidad es el motivo fundamental. El segundo espacio, que coincide con la segunda parte, es el Sur de la Argentina, Bariloche, lugar en el que se urde la verdadera trama de la novela, se desenlazan las historias y se desencadena un final, tal vez inesperado, que sorprende. El narrador, sin nombre, en primera persona, cuenta que su abuela Lela había perdido a su hija y a su nieto, ya que le contaba que su mamá -hija

\footnotetext{
${ }^{22}$ Federico Moura nació el 23 de octubre de 1951 en la ciudad de La Plata, Provincia de Buenos Aires. Cuarto de un grupo de seis hermanos (el mayor de los cuales, Jorge, fue secuestrado por la dictadura militar en 1977 y se encuentra desaparecido desde entonces). Es la letra de una canción, un rock nacional, titulado "Amor Descartable" de la banda Virus, cuyos versos se completan con los siguientes: "Escucharte a mi lado hablar/ aunque estemos distantes, /es el mundo tan poco sensual/que no pudo aliviarme. /Vos sos mi obsesión,/ quisiera atraparte. /Vos sos mi destrucción,/ no puedo dejar de pensar./ Tengo que ordenar/ esta confusión,/ quiero estar libre/ para un nuevo amor".
} 
de Lela-, durante el cautiverio de la ESMA, había tenido otro hijo. Se trata asi de la historia que va a narrar un hijo de desaparecidos, que curiosamente nunca habla de su madre, y tampoco le interesa saber de su padre, pero que busca conocer, además de su identidad, si existió o no ese "hermano" supuestamente nacido en cautiverio, la travesti Maira, también hijo de desaparecidos, del cual él se enamora. De hecho, el narrador se autodefine como bisexual.

De esta manera, hay un Estado ideologizado y diversas situaciones de "búsqueda" y una persecución permanente de personas y territorios. Lela busca a su otro nieto desaparecido; el narrador busca elementos para poder contar su historia; Maira, su posible hermana-hermano travesti, también buscaba a una hermana que había nacido en cautiverio; asimismo, hay búsqueda de espacios -la casa de Moreno que se pierde precisamente por estar su dueño, que es el narrador, mucho tiempo ausente en la interminable "búsqueda" de personas que pueden coadyuvar al reencuentro con el pasado-, y de territorios: ESMA, sede de HIJOS sin padres; y también sectores de Buenos Aires, de Bariloche-, entre otras muchas situaciones similares.

En la primera parte se produce el encuentro con Romina, que constituye uno de los episodios fundamentales. Romina militaba en HIJOS, quienes realizaban "escraches" que eran una forma de revancha o de justicia por mano propia. También aparece Ludo, novia de Luis, su ex vecino, que militaba en HIJOS, y cuya tía había desaparecido en Córdoba. El narrador y Romina tienen sueños compartidos que les permitían ver hacia adelante una visión no apocaliptica ni tediosa de la vida, sino pacífica y frágil y, fundamentalmente, feliz, pero queda embarazada y se va sin rumbo conocido para el narrador, y allí se inicia otra búsqueda.

Surgen en esta parte cuestiones propias de la "realidad" de aquel momento, como el pago de las indemnizaciones que ofrecía el gobierno a los damnificados por el proceso, y la aparición de la figura del "travesti", tema éste que llega a constituirse en el otro elemento clave de la novela. Aparece Maira -el otro personaje importante, también eje en la narración-, su supuesto hermano en cautiverio, cuyo proyecto era matar represores. Un travesti de quien se enamora el narrador. Una presencia ambigua entre posible infiltrado policial en Hijos, a posible vengador de genocidas: un posible neo-desaparecido. Maira permite abrir una exploración del inconsciente político pero también del amor fraterno y romántico. 
Luego irrumpe un plano de irrealidad, el inicio de una etapa negra cargada de pesadillas, donde la búsqueda por la recuperación de recuerdos -los de su infancia-; de lugares -el zapallar, espacio donde escuchó la verdad de su vida en boca de sus abuelos-; y de personas Maira, fundamentalmente-, se traslada por caminos oníricos.

\section{EL ENCUENTRO}

En la segunda parte, que se desarrolla integramente en Bariloche, el protagonista más importante que acompaña al narrador es un sujeto llamado "el Alemán". Es un hombre salvaje, cruel, astuto e impredecible, quien gustaba hablar de sus encuentros y aventuras nocturnas con travestis, y que se convertirá en el núcleo del desenlace de la novela: se enamora del narrador y juntos esperan construir un proyecto futuro de amor. El mal trato era la nota señera y la que lo distinguía en su relación con estos personajes travestistas:

Decía ayer, después de cenar, agarré la camioneta y me fui para Centenario. Esos maricones parecen minas, eh. Hay uno que es medio orejudo, je. ¿Conocen el chiste?, para agarrarse mejor cuando te lo culeás. Ese debe ser medio loco, ya un dia lo voy a agarrar para que le chupe las ruedas a la camioneta, que se chupe la bosta de las ruedas, a ver qué dice (...) al de ayer lo hice recagar en las patas, lo subí atrás y lo esposé a la barra antivuelco, después salí a la ruta y entré a zigzaguear, decí que estaba atado, el maricón, si no salía volando y en la zanja andá a reconocerlo. Eso un día. Otro: era una rubia, la cargué y me la llevé para el campo de allá (...) esos putos son más fantasiosos... (Bruzzone 2008: 115).

Es importante destacar que en esta segunda parte aparecen recién, y en dos oportunidades, alusiones al nombre del libro: los "topos". El sustantivo "topo", cuyo significado se registra en el Diccionario de la Real Academia Española y en sus cuatro acepciones, señala en sus diferentes alternancias, ya animal, ya en relación con personas, algo 
despreciable y ruin. ${ }^{23}$ La primera referencia está relacionada con la descripción que al narrador le hacen de su padre:

¿Y papá?, pregunté. Tu papá es éste, dijo mi abuelo. En una de las imágenes, la amiga de mamá abrazaba a un joven de pelo engominado, anteojos para el sol, cigarrillo en la boca y campera negra de cuero. Ahora que lo pienso, si el fondo no hubiera sido de cactus y montañas azules, si hubiera habido una ruta, una estación de servicio, un Cadillac, aquello podía pasar por la promoción de una película de la época. ¿Ése es? Sí, dijo Lela. Parece un colectivero, ¿no es cierto?, dijo mi abuelo. Exacto, un colectivero, dijo Lela, ese topo siempre pareció algo distinto a lo que era (Bruzzone, 2008: 134). ${ }^{24}$

La segunda está vinculada con la vida del narrador, cuando en el proceso de transformación para ser travesti, en su búsqueda de clientes para perfeccionar ese nuevo tipo de identidad, sugestivamente lo señalan como traidor y mala persona, y se encuentra con otro colega travesti que lo marca también como extraño y distinto, en consecuencia, más atractivo que el resto. Un verdadero “topo indigno”. Le manifestó:

Una yegua de labios fucsias y ojos grises una vez me paró en seco en la calle y me dijo: vos putita, sos un topo, asomás la cabeza en cualquier lado, ¿entendés?, sos un topito lechero pero sin la teta de mamá -así dijo-:"topito lechero". Siguió: y tené cuidado con la nieve, porque la nieve te tapa enseguida y con tal de sacar tu cabecita la vas a sacar en

\footnotetext{
${ }^{23} 1$.- Mamifero insectivoro del tamaño del ratón, de cuerpo rechoncho, cola corta y pelaje negruzco suave y tupido; hocico afilado, ojos pequeños y casi ocultos por el pelo; brazos recios, manos anchas, cortas y robustas, cinco dedos armados de fuertes uñas que le sirven para socavar y apartar la tierra al abrir las galerias subterráneas donde vive. Se alimenta de gusanos y larvas de insectos.

2.- Persona que tropieza en cualquier cosa, o por cortedad de vista o por desatiento natural. Diccionario de la Real Academia Española, 1992.

3.- Persona de cortos alcances que en todo yerra o se equivoca. Diccionario de la Real Academia Española, 1992.

4.- Persona que, infiltrada en una organización, actúa al servicio de otros. Diccionario de la Real Academia Española, 1992.

${ }^{24}$ El subrayado nos pertenece.
} 
Alteridad e identidad en la novela Los Topos de Félix Bruzzone. La temporalidad inscripta en la historia literaria argentina | 87

cualquier lado y zácate, chau cabecita, yo sé por qué te lo digo y me mostró unas cicatrices horribles a la altura del ombligo. Pensé que había estado con el Alemán, que el tipo la había maltratado (Idem.: 147).

Dos menciones a los "topos" que se encarnan curiosamente en el padre -que no conoció nunca-, y en el hijo, que nunca buscó a su padre, como tampoco buscó rastros de su madre. Luego el narrador concibe un plan, que era hacerse pasar por travesti, para vengarse del Alemán y hacer justicia matándolo:

El plan era hacerme pasar por travesti, dejarme levantar por el Alemán, convertirme en su chica travesti favorita, y una noche, con la determinación del que esperó una vida entera el momento de hacer justicia, matarlo (...) Yo convertido en la chica hermosa y el Alemán en el horrible verdugo ajusticiado en una obra de un acto único de justicia hermosa: el primer paso hacia el hallazgo de mi verdad familiar y de todas las verdades posibles (Idem: 143).

Al final de la historia del relato hay una vuelta de tuerca significativa, ya que el narrador se convierte de victimario en víctima de la situación. Hay un cruce de líneas y el desenlace resulta así novedoso y sorprendente, porque asistimos a un desplazamiento que afecta a su condición de abandonado en situación de búsqueda. Maira, la travesti buscada y amada, continúa en la persecución de los terroristas de Estado, y él abandona esa búsqueda que con el pasar de los días pierde fuerza, y elige permanecer junto al Alemán. Es posible que se dé cuenta de que lo que busca está en el presente de su historia junto al Alemán, en el cual ambos, juntos, el narrador sin nombre y el Alemán buscarán a Maira en un futuro. $¡ \mathrm{O}$ no?

Finalmente, es interesante destacar que si bien en la novela se habla de la permanente búsqueda de seres desaparecidos, en el mismo discurso novelístico el narrador comenta y describe en el presente de su historia que narra, el secuestro de Maira por parte de los secuestradores. Realidad pasada y ficción del presente de la narración se entremezclan dando como resultado la inauguración de una escritura diferente. 


\section{ALGUNAS REFLEXIONES FINALES}

- Los hechos ocurrieron.

- Las víctimas también.

- Aún, muchos de los genocidas intelectuales y los ejecutores viven en libertad.

- ¿Es posible generar perdón sin arrepentimiento?

- ¿Los genocidas pidieron perdón?

- ¿Las cicatrices implican olvido?

- Los testimonios literarios, fílmicos, jurídicos y culturales son los mejores argumentos para mantener encendido y vivo el recuerdo de las víctimas.

- Los Topos fue examinada para mostrar que las generaciones siguientes no pueden suplantar a las víctimas y es muy "frágil" el planteo de justicia con perdón y sin olvido. El olvido es un enemigo de la Historia y todo lo que realicemos para dignificar la Democracia y evitar la humillación y la discriminación es poco frente al terrorismo político de aquellos que detentaron el poder. Sólo el compromiso y la participación ciudadana pueden ejercer cierto control sobre los poderes políticos.

\section{CONCLUSIONES}

Los Topos es una historia de búsquedas y de desapariciones, de encuentros y de desencuentros, de intrigas y de misterios, en la que aparentemente se arriba a un final sorpresivo. Esta original y sorprendente novela, por la temática diferente que aborda y en tanto testimonia una realidad socio-política-cultural nefasta de un pasado bastante reciente, además de novedosa por el abierto planteo genérico, tiene como protagonistas a tres personajes que se constituyen como principales: el narrador (sin nombre), Maira y el Alemán. Pero lo relevante de la novela es que es la voz de un hijo de desaparecidos quien cuenta su historia, o la historia que le contaron sus abuelos acerca de sus padres y de lo acontecido en la sociedad. El que narra se encuentra con personajes que favorecen el avance del relato y coadyuvan a transformar su identidad como sujeto deseante. Personaje que vive situaciones límites y en esa búsqueda está en juego la de su propia identidad sexual. Maira, en síntesis, es un travesti, del que se enamora el que no tiene nombre. Maira pasa de ser posible policía infiltrado en Hijos, a posible vengador de genocidas; de posible hermano nacido en cautiverio, a posible neo- 
Alteridad e identidad en la novela Los Topos de Félix Bruzzone. La temporalidad inscripta en la historia literaria argentina | 89

desaparecido. Finalmente, el Alemán, hombre cruel y poderoso que se enamora del narrador, lo encierra junto a un lago y lo convence para que la cirugía lo convierta en una travesti deseada, en su futura compañera de vida. En esta novela realmente sorprende el final -tal vez inverosímil-, donde se puede observar un desvío de los objetivos de "búsqueda" tan presentes en la primera parte, como también en fragmentos relevantes de la segunda, desvío que se concreta en "hallazgo- encuentro" del otro a través del amor, tal vez como única posibilidad de rescate y de reivindicación personal.

Nace así con Los Topos una poética y una estética diferentes, que despliegan un quiebre generacional en lo literario y que se apropian de una variedad de discursos heredados sobre la historia nacional argentina.

Novela en la que se registrar "otra" mirada. Mirada novedosa, una mirada trágica y cómica a la vez, que puede entenderse como una forma de crítica político-social. Félix Bruzzone utilizó la palabra como herramienta para encontrar la luz, en su doble vertiente, en la ficción pero también en la "realidad" de su vida.

\section{BIBLIOGRAFÍA}

ARISTÓTELES. Poética. Buenos Aires: Gradifco SRL, 2008.

AVELLANEDA, Andrés. Militares y Literatura: el Canon que no Supieron Conseguir. En: Realismo, Antirrealismo, Territorios Canónicos. Argentina Literaria Después de los Militares. 1982.

BRUZZONE, Félix. Los Topos. Buenos Aires: Mondadori, 2008.

DICCIONARIO DE LA LENGUA ESPAÑOLA. Vigésimo Primera Edición, Real Academia Española. Impresión: Mateu Cromo. Madrid: España, Artes Gráficas, 1992.

FOSTER, David W. REVISTA LA INTEMPERIE. Publicada en Revista Chasqui, Vo. 33, Número 1, Mayo 2004, Argentina.

REATI, Fernando. Nombrar lo Innombrable. Buenos Aires: Editorial Legasa, 1992. 
SARLO, Beatriz. Política, Ideología y Figuración Literaria. En: Ficción y Política. La Narrativa Argentina durante el Proceso Militar, Buenos Aires, Alianza, 1987.

Sobre "Los Topos", de Félix Bruzzone. "Condición de búsqueda". En: Perfil, Suplemento Cultural/ Ensayo, Domingo 7 de diciembre de 2008.

SOSNOWSKI, Saúl (compilador). Represión y Reconstrucción de una Cultura: el Caso Argentino. Buenos Aires: Eudeba, 1988.

Recebido em: 26/08/2016

Aceito em: 19/09/2016 